\title{
CONTRIBUIÇÕES DA FAMÍLIA NA FORMAÇÃO INTEGRAL DA CRIANÇA DE O A 06 ANOS JUNTO ÀS AULAS DE EDUCAÇÃO FÍSICA
}

CONTRIBUTIONS OF THE FAMILY IN THE COMPREHENSIVE TRAINING OF CHILDREN FROM O TO 06 YEARS OF AGE IN PHYSICAL EDUCATION CLASSES

Fábio Júlio Serafim da Silva

Secretaria de Educação do Estado de Pernambuco E-mail: fabiojulioo.22@gmail.com

\section{RESUMO}

O principal objetivo deste trabalho é fazer uma reflexão a partir da Educação Física inserida na Educação Infantil, abordando o quanto é importante a parceria entre a família e os professores que atuam nesse ciclo educacional, com foco na contribuição junto ao desenvolvimento Biopsicossocial. Para tanto, foi utilizado como metodologia uma revisão literária, selecionado artigos, revistas, livros, relatórios de pesquisas, teses e monografias, que são especializadas no tema em questão. No processo de seleção do material analisado, utilizamos os seguintes critérios: autores referencias no tema a nível nacional e mundial, data das publicações, também se levou em consideração fontes de confiança. Foram selecionados 30 textos que tinham como destaque o tema central da nossa pesquisa. Diante desta reflexão, evidencia-se a necessidade de levar adiante para toda sociedade, em torno da importância da parceria entre escola e familiares junto ao processo de ensino aprendizagem das crianças de 0 a 06 anos. Nesse sentido, o papel pedagógico da Educação Física nessa fase é associado ao que é oferecido durante toda a sua carreira dentro da Educação Infantil. A família tem que saber e acompanhar como o filho se comporta não só na escola, mas de maneira geral, sua base vem de casa e as aulas de Educação Física complementarão seu desenvolvimento integral.

Palavras-chave: Educação Infantil; Biopsicossocial; Ensino aprendizagem.

\section{ABSTRACT}

The main objective of this work is to reflect on Physical Education inserted in Early Childhood Education, approaching how important the partnership between the family and teachers who work in this educational cycle is, with a focus on contributing to the Biopsychosocial development. Therefore, a literary review was used as a methodology, selected articles, magazines, books, research reports, theses and monographs, which are specialized in the subject in question. In the process of selecting the material analyzed, we used the following criteria: authors who are national and world-referenced on the subject, date of publications, and trusted sources were also taken into account. Thirty texts that highlighted the central theme of our research were selected. In view of this reflection, the need to take it forward for all of society is evident, around the importance of the partnership between school and family members in the teaching-learning process of children aged 0 to 06 years. In this sense, the pedagogical role of Physical Education at this stage is associated with what is offered throughout its career in Early Childhood Education. The family has to know and monitor how the child behaves not only at school, but in general, his base comes from home and the Physical Education classes will complement his integral development.

Keyword: Child education; Biopsychosocial; Teaching and learning. 


\section{V.10 N.1 (2022) ISSN: $2317-434 X$}

\section{INTRODUÇÃO}

Sabendo de toda a importância de se trabalhar a Educação Física na Educação Infantil é à base de todo e qualquer cidadão, planejada de forma coerente, traçada por objetivos concretos e pensando na criança no seu aspecto Biopsicossocial, o estudo em questão vem traçar e relacionar o bom envolvimento, participação na escola e fora dela, perante a família quanto ao desenvolvimento social, cognitivo, motor e afetivo, mostrando a relevância da união em um mesmo objetivo: Educação Física incorporada à assistência familiar, pensando e ao mesmo tempo estimulando as crianças dessa modalidade de ensino. Segundo Schettini Filho (1997, p.13):

O ambiente torna-se para a criança o campo em que será processado e aperfeiçoado seu potencial, propiciando, desse modo, condições em habilidades. Todo desenvolvimento ocorre em função de um ambiente interno (físico, fisiológico e psicológico) e de um externo (tudo o que faz parte da realidade objetiva). Se pensarmos na atuação dos pais e professores, identificaremos uma verdade simples e de alta relevância: o processo educacional é responsável por uma parte considerável da forma que cada pessoa dará à sua vida. Na prática, o desenvolvimento está, na sua maior parte, nas mãos daqueles que servem de referências para a vida da criança.

Nessa correlação o envolvimento familiar é algo de grande relevância para aproximar os conteúdos da Educação Física à convivência da criança na escola, em casa e em lugares que a mesma passará a frequentar, levando em consideração cada detalhe que interfere de forma positiva e negativa, principalmente nessa fase a criança vive um momento grandioso de desenvolvimento. Assim, nós profissionais da educação assumimos o papel tão quanto o dos familiares, espelho para as crianças, e nesse sentido o trabalho debatido e dividido nos dois lados é altamente importante para o desenvolvimento da mesma nos campos escolar, familiar e social (SOARES, 2010).

A Educação Infantil é uma etapa crucial para a formação da base da criança quando traçada de forma que venha a estimular a mesma, terá uma sustentação bem construída, pensando nas suas necessidades particulares o meio interfere diretamente no seu desenvolvimento. Nesse ponto, a união entre o contexto escolar dentro das aulas de Educação Física, com a participação familiar no complemento dessa aprendizagem, vem a se tornar algo de bastante contundência (PEREZ, 2007).

Quando falamos no papel da Educação Física junto à família, observamos como essa disciplina é importante na formação integral da criança da Educação
Infantil. Prova disso é todo amparo que a Educação Física estimula e oferece aos alunos deste ciclo educacional, a parceria deve ser construída baseada no que a criança tem como realidade e o seu meio, para que assim a interferência seja certeira diante das necessidades a serem trabalhadas, como exemplo podemos citar: parte do desenvolvimento motor, cognitivo, afetivo e social. Ambos estejam preparados para oferecer a esse aluno situações que o desenvolvam, isso depende da família e escola uma parceria necessária e coerente.

Com isso, é possível percebermos que uma Educação Física que possui tais características e que se propõe a tratar de elementos como o desenvolvimento cidadão, a ação reflexiva, o exercício de posicionamentos e atitudes críticas para a melhoria da qualidade de vida, necessita fazer parte de um processo educacional, que não possua características como a fragmentação e o isolamento de seu trabalho, seja em relação aos outros componentes curriculares, como também e principalmente em relação às intenções e ações da família e da escola (BEDINI, 2016).

A família deve também exercer seu papel quanto a manter e auxiliar a escola no bom relacionamento das crianças, não apenas pensando em resultados sem que haja o comprometimento para andar junto aos professores, com destino a formação desta no aspecto integral, característica essa que a Educação Física cuidadosamente se preocupa. Partindo destas informações, pretendemos apresentar o quão é importante à presença familiar no processo de ensino aprendizagem da criança de 0 a 06 anos como auxílio para as aulas de Educação Física.

\section{MATERIAIS E MÉTODOS}

A pesquisa baseia-se em uma revisão bibliográfica, foram utilizados bibliografias de diferentes autores, revistas e artigos científicos, livros, relatórios de pesquisas, teses e monografias, que são especializadas no tema em questão que retratam o tema, que visam à importância do papel familiar junto à criança de 0 a 06 anos nas aulas de Educação Física, tendo como reflexo a solidificação da infância.

A Pesquisa bibliográfica busca a resolução de um problema por meio da análise das referenciais teóricos publicados, analisando e discutindo as várias contribuições científicas. Nesse tipo de pesquisa trazemos subsídios para o conhecimento sobre o que foi pesquisado, como e sob que enfoque ou perspectivas foi abordado o assunto apresentado na literatura científica (BOCCATO, 2006).

No processo de seleção do material analisado, utilizamos os seguintes critérios: autores referencias no tema a nível nacional e mundial, data das publicações, 


\section{V.10 N.1 (2022) ISSN: 2317-434X}

também levou-se em consideração fontes de confiança. Foram selecionados 30 textos que tinham como destaque o tema central da nossa pesquisa. Os estudos analisados foram publicados entre (1981-2016).

\section{RESULTADOS E DISCUSSÕES}

Quando se fala no aspecto epistemológico, demorou até que as Ciências Sociais e Humanas utilizassem a criança e a infância como objetos centrais de suas pesquisas. Demorou mais tempo ainda para que as pesquisas considerassem em suas análises as relações entre sociedade, infância e escola, entendendo a criança como sujeito histórico e de direitos, tendo como eixo de suas investigações o registro das "falas" das crianças. A busca pela interpretação das representações infantis de mundo é objeto de estudo relativamente novo, que vem objetivando entender o complexo e multifacetado processo de construção social da infância e o papel que a escola vem desempenhando diante desta invenção da modernidade. Nesta direção, como afirmado anteriormente, os estudos são raros, ainda mais no Brasil (CORSARO, 2003).

Para a Organização Mundial da Saúde (OMS) a infância é o período da vida humana compreendido do nascimento até os 10 anos de idade, e a pessoa nessa fase recebe a denominação de criança. Mas, ao buscarmos no dicionário a definição da palavra criança encontramos que a mesma é um "ser humano de pouca idade, menino ou menina; párvulo. Pessoa ingênua, infantil: não desconfia de nada, é uma criança" (FERREIRA, 1986).

No decorrer da história, a criança tem ocupado diferentes posições, dependendo do valor que a sociedade lhe dava. O historiador Philippe Ariés, em sua obra "História Social da criança e da família", nos traça uma trajetória de como a criança vem sendo tratada ao longo dos séculos, ressalta, por exemplo, que a infância sempre esteve ligada à ideia de dependência, assim a criança, no decorrer da história, vem sendo tratada como alguém com perspectiva de "vir- a- ser", mas que ainda não é (ARIÉS,1981).

A fase vivida pela criança de 0 a 06 anos lhe proporciona momentos de aprendizagem e desenvolvimento integral. Ela observa tudo que faz parte do seu meio, pode até parecer que não, mas cada momento na vida dessa criança é o seu amparo de referência. Nesse ciclo da educação ela começará a quebrar barreiras e se identificar com aulas prazerosas, e nesse sentido a Educação Física se encaixa perfeitamente, onde o prazer é associado ao lúdico, e este incorporado ao aprender, o famoso "aprender brincando". Ainda vale expor que momentos que favoreçam o crescimento e desenvolvimento do aluno da Educação Infantil devem ser vivenciados e oportunizados em todos os campos onde a criança esteja. Não adianta somente a escola proporcionar momentos assim e a família não, ou vice e versa, é preciso que haja uma parceria para que o resultado final seja significante para todos, e principalmente a criança. Nessa perspectiva Antunes levanta que:

Se a ciência mostra que o período que vai da gestação até o sexto ano de vida é o mais importante na organização das bases para as competências e habilidades que serão desenvolvidas ao longo da existência humana, prova-se que a Educação Infantil efetivamente é tudo, mas é essencial que possamos refletir sobre como fazê-la bem e descobrir que esse bem fazer vai muito além de um "desejo" sincero e um "amor" pela criança. Para que a sentença ganhe corpo e forma é essencial que o educador infantil seja "preparado" e "competente"[...]. (ANTUNES, 2009, p. 9).

O desenvolvimento educacional da criança é um processo de etapas ao longo da vida, havendo várias mudanças em seu comportamento físico, cognitivo e mental. Em cada fase se obtém uma característica particular, variando de criança para criança, o que é bem natural. Nesse sentido escola e professor devem se preparar também, para conviver com a criança, ajudandoa a evoluir, contando com a parceria da família que é o elo principal nessas etapas.

Durante todo o seu crescimento e desenvolvimento a criança tem sempre suas reações e desejos que dependem da sua satisfação em realizar o que é procurado; quando a criança chega à escola, esta deseja ser amada e bem aceita pelos coleguinhas e professores, quando isso acontece desperta nela um olhar de curiosidade e de aprendizagem, nesse sentido cabe ao professor planejar um espaço que envolva os interesses da criança e também a família complementar esse trabalho em casa e fora da escola.

Em toda sua vivência a criança evolui de acordo com as experiências e sua particularidade, cada fase do desenvolvimento tem uma característica que é desenvolvida de acordo com seu crescimento. De acordo com Piaget (1971, p.110): "O indivíduo (a criança) aprende construindo e reconstruindo o seu pensamento, através da assimilação e acomodação das suas estruturas. Esta construção do pensamento".

$\mathrm{Na}$ construção e reconstrução do seu mundo a criança voa na sua imaginação e descobre muitas coisas, essas são indispensáveis para seu desenvolvimento e crescimento. Também nesse ponto a mesma cria dentro de 


\section{V.10 N.1 (2022) ISSN: 2317-434X}

sua realidade tudo que é dela por direito, a mesma brinca com ele e aprende variando de acordo com o que é oferecido ou não para ela em termos sociais, culturais e entre outros fatores.

Portanto, as fases da caracterização da criança na idade abordada nesse trabalho incorpora-se aos momentos vividos em casa, na sua escola e na sociedade no geral, basta oferecer vias que façam com que a aprendizagem seja mais acessível, com isso será gerado bons frutos para sua formação como individuo sem quebrar o que ela mais gosta: brincar, aprender e ser feliz. Cabe salientar que os momentos propostos aos pequenos devem sempre ter um reforço por parte do professor (a) e também da família seja, em casa ou no âmbito escolar, para que possa estimular uma reflexão sobre a prática de atividades consideradas mais complexas e as do cotidiano, sem que se deixem levar pelas técnicas informativas dos dias atuais. Isso muitas vezes interfere em alguns pontos da vida das crianças, como exemplo prático podemos citar o crescimento do sedentarismo que vem se alavancando dia pós dia pelo fato das crianças não serem estimuladas aos hábitos saudáveis desde cedo.

Nessa perspectiva de importância, a Educação Infantil proporciona um espaço em que a criança aprende brincando, socializa-se com outras crianças, conversa, desenvolve seus aspectos cognitivo, social, afetivo e motor. Justamente isso é fundamental já que é a primeira experiência educacional da criança fora do ambiente familiar, onde sente-se protegida. Neste momento destacamos a importância da Educação Física na Educação Infantil, pois a partir dela, oportunizamos a criança: o movimento, a linguagem corporal, introduzidos ao fator cultural por meios de atividades lúdicas que incorporam os pilares da Educação Física, desde jogos e brincadeiras, dança com os brinquedos cantados e entre outros. Relacionado ao desenvolvimento da criança, Vygotsky (1984, p. 75) afirma que o mesmo passa por diferentes etapas sendo a interação social alavancada pela família, passando pela escola e sociedade uma das principais:

Primeiro no nível social, e, depois, no nível individual; primeiro entre pessoas (interpsicológica), e, depois, no interior da criança (intrapsicológica). Isso se aplica igualmente para atenção voluntária, para a memória lógica e para a formação de conceitos. Todas as funções superiores originam-se das relações reais entre indivíduos humanos.

Em cada ambiente onde a criança esteja inserida é oportuno transformar e montar situações para que cada fase do seu desenvolvimento integral seja trabalhado com o intuito de desenvolvê-la de forma sadia e natural, onde a mesma não se sinta pressionada a realizar ou montar algo. Nessa perspectiva, a ludicidade deve sempre estar lado a lado aos objetivos propostos, no nosso caso como profissionais da área de Educação Física mais ainda, pois, vivenciar o lúdico nas nossas aulas é uma chave de ligação positiva ao desenvolvimento (quando trabalhada de forma correta, e não o lúdico sem objetivos concretos).

Neste sentido o trabalho do professor de Educação Física em parceria com a família traz objetivos mais concretos para o desenvolvimento da mesma nesse ciclo educacional. O seu desenvolvimento ocorre através de experiências, estímulos e a interação com o meio que vive, em que cada fase de seu desenvolvimento tem uma característica de acordo com as relações: família, escola e sociedade.

O professor de Educação Física deve estimular as crianças a brincar, e a melhor forma é brincar junto com elas. Segundo Kamii (1991, p. 291 e 292, grifo do autor): "a melhor maneira de o professor ensinar jogos é ele próprio ser um jogador, que se submete às mesmas regras como qualquer outro jogador". Nesse relacionamento entre professor, família e escola a aprendizagem da criança torna-se bem alavancada. Sabemos, também, que dentro do processo de desenvolvimento integral é importante e necessário a complementação de fatores que ajudem a chegar no patamar de bons estímulos, esse desenvolvimento varia de uma para outra.

Refletir sobre Educação Física na Educação Infantil é desafiador, sobretudo quando pensamos em possíveis tensões (trabalho, metodologia, conteúdos, prática etc.) existentes na presença do profissional de Educação Física inserido no ensino de zero a seis anos. Estamos falando da relação entre professor especialista em Educação Física atuando junto com ao Pedagogo. A grande preocupação em torno desse assunto é de assumirmos já na Educação Infantil um modelo "escolarizante", organizado em disciplinas e com uma abordagem fragmentária de conhecimento, tem que haver um complemento de ensino entre os diferentes profissionais e lógico, os familiares (AYOUB, 2005).

Sendo assim, esse momento de tão grande valia para o desenvolvimento integral da criança de 0 a 06 anos requer da família e do professor de Educação Física bastante cuidado e interferência, quando necessário. Devese estimular sempre fatores que venham a influenciar positivamente, quando a família não tem o conhecimento necessário para que proporcione a criança estímulos deve haver a pesquisa para saber como e de que forma atuar, nesse sentido o acompanhamento escolar é favorável, a escola e órgãos sociais devem também levar a todos os responsáveis conhecimento em lidar com cada momento e fase do desenvolvimento da criança na Educação Infantil 


\section{V.10 N.1 (2022) ISSN: 2317-434X}

dentro da sua cultura, religião, meios e acessibilidade.

Podemos observar características relacionadas ao desenvolvimento integral da criança de 0 a 06 anos, de acordo com os estudos de grandes referências do contexto que já foram citados e também serão analisado posteriormente no nosso estudo, baseia-se nas teorias de Jean Piaget, Henri Wallon e Lev Semi Vygotsky. Autores esses que se destacam mundialmente nos estudos da psicologia do movimento voltada para a Educação, tendo como foco o desenvolvimento infantil.

Iremos apresentar as propostas de trabalho relacionado ao desenvolvimento da criança, os autores Jean Piaget, Henri Wallon e Lev Semi Vygotsky nos ajudam a esclarecer as principais ideias para a área de Educação Física neste ciclo de ensino, focando a aprendizagem integral, além de mencionar o quanto escola e família são fundamentais nos aspectos: cognitivo, motor, afetivo e social, respectivamente.

\section{Desenvolvimento Cognitivo}

Jean Piaget (1895-1980) ganhou notoriedade como psicólogo infantil, mas não era à criança que sua atenção científica estava voltada; sua preocupação era pela capacidade do conhecimento humano e pelo seu desenvolvimento. E como, na sua visão, a criança é o ser que mais notoriamente constrói conhecimento, suas pesquisas e observações voltaram-se para a construção e aquisição de conhecimento pelos homens na idade infantil e na adolescência. Biólogo por formação, psicólogo pela classificação profissional, mas epistemólogo pelo conjunto de sua obra, Piaget descobriu, influenciado pelos seus interesses em psicopatologia, psicanálise, lógica e filosofia, "que no estudo da inteligência infantil a biologia se vincula à filosofia das ciências naturais" (PÁDUA, 2009).

Na teoria Piagetiana, há dois termos que não podem deixar de ser mencionados e explicados: assimilação e acomodação. Segundo Piaget (2007), toda atividade do sujeito envolve esses dois movimentos. Diante disso, Piaget, denominou a assimilação e a acomodação de funções invariantes, visto que, são funções que não mudam por causa do desenvolvimento (LEFRANÇOIS, 2008).

Em uma forma geral, notamos o quanto todo estudo de Piaget esclareceu e criou em outros estudos um norteador de ideias, já que a aprendizagem integral da criança da Educação infantil passa por várias alterações devido a sua realidade. Observamos também, que neste processo o fator cognitivo é abordado à relação da família e escola ganham caráter primordial no crescimento e desenvolvimento de cada criança. E no estudo em questão trazemos justamente esse ponto como foco, a importância dos pais atuando junto dos professores de Educação Física no processo de ensino aprendizagem dos alunos deste ciclo educacional.

Estando no papel de profissionais ou familiares, devemos procurar meios com que a criança no seu desenvolvimento cognitivo possa adaptar-se e se organizar diante das situações e objetos que ela tenha ou venha a ter acesso, a relação de organização de um para com o outro facilita as vias onde a criança utilize como meios de ligação ao desenvolvimento. Com isso, nessa análise do estudo de Piaget fica perceptível que toda a influência da família dentro do ponto desenvolvimento cognitivo no eixo integral, implica que a cada descoberta da criança a interação entre pais e escola contribui e muito.

\section{Desenvolvimento Motor e Afetivo}

Henri Walon (1879-1962) médico francês desenvolveu vários estudos na área da neurologia, enfatizando a plasticidade do cérebro. Walon propôs o estudo integrado do desenvolvimento infantil, contemplando os aspectos da afetividade, da motricidade e da inteligência. Para ele, o desenvolvimento da inteligência depende das experiências oferecidas pelo meio e do grau de apropriação que o sujeito faz delas. Nesse sentido, os aspectos físicos do espaço, as pessoas próximas, a linguagem, bem como os conhecimentos presentes na cultura contribuem efetivamente para formar o contexto de desenvolvimento. O mesmo também assinala que o desenvolvimento se dá de forma descontínua, sendo marcado por rupturas e retrocessos. A cada estágio desse desenvolvimento infantil há uma reformulação e não simplesmente uma adição ou reorganização dos estágios anteriores. (CRAIDY, ELISE. 2001)

Nesse sentido, a passagem dos estágios de desenvolvimento não se dá linearmente, por ampliação, mas por reformulação, instalando-se no momento da passagem de uma etapa a outra, crises que afetam a conduta da criança. Conflitos se instalam nesse processo e são de origem exógeno quando resultantes dos desencontros entre as ações da criança e o ambiente exterior, estruturado pelos adultos e pela cultura e endógenos e quando gerados pelos efeitos da maturação nervosa. Assim, esses conflitos são propulsores do desenvolvimento, a diversificação gera também dentro da infância fatores que somam o desenvolvimento, variando de acordo com cultura, meio e entre outros. Assim, o desenvolvimento do ser sucede-se em fases com predominância afetiva e cognitiva (GALVÃO, 1995). 


\section{V.10 N.1 (2022) ISSN: 2317-434X}

Dessa forma, dentro do desenvolvimento integral da criança o fator motor e afetivo com certeza necessita do professor e da família uma postura centrada e com conhecimentos diferenciados em ambas as partes do mesmo, ou seja, estimular positivamente este desenvolvimento, a escola deve oferecer vias para levar informação com qualidade para que os familiares exerçam seu papel de fato, já que como referenciado no nosso trabalho a construção do desenvolvimento da criança da Educação Infantil é ligada de forma clara as suas referências.

\section{Desenvolvimento Social}

Vygotsky (1896-1934) Foi o primeiro psicólogo moderno a sugerir os mecanismos pelos quais a cultura torna-se parte da natureza de cada pessoa ao insistir que as funções psicológicas são um produto de atividade cerebral. Conseguiu explicar a transformação dos processos psicológicos elementares em processos complexos dentro da história. Vygotsky enfatizava o processo histórico-social e o papel da linguagem no desenvolvimento do indivíduo. Sua questão central é a aquisição de conhecimentos pela interação do sujeito com o meio. Para o teórico, o sujeito é interativo, pois adquire conhecimentos a partir de relações intra e interpessoais e de troca com o meio, a partir de um processo denominado mediação (ARAUJO; FLORIANA, 2006).

O campo social destacado nesse ponto por Vygotsky é embaçado por qualquer relação da criança em ambientes diferentes e com pessoas diferentes, esboça o quanto o papel da Educação Física é visto como essencial nessa relação basta notar o quanto nossa área preza o fator social e suas relações. Cada momento de socialização é de suma importância.

Podemos observar também que a socialização, o brincar de criança para criança desperta desde cedo com trabalho em equipe, a cooperação, o companheirismo, que são fontes do desenvolvimento social-humano, onde incorpora-se as nossas aulas grandes estímulos de viver em uma sociedade diversificada e que saibamos respeitar as diferenças entre as relações culturais, religiosas e etc. O papel do professor e da família neste processo de aprendizagem social é oferecer ações que liguem cada momento a vida da criança à sua relação com outras crianças e pessoas, como prova da importância da socialização na Educação Infantil.

Em cada momento da Educação Infantil a Educação Física é baseada em fatores que somem quanto ao desenvolvimento integral de cada criança, e com essa análise cada ponto da sua aprendizagem deve possibilitar uma educação que vise e desenvolva não somente pontos isolados, mas sim, integralmente. Mediante algumas análises cientificas, observa-se que é necessário estabelecer uma parceria entre a família na escola, com vistas a ajudar o profissional de Educação Física na formação da criança, aproximando-se da realidade escolar, incentivando em casa e fora do ambiente familiar, de forma que o professor deve vivenciar de dentro para fora, ou seja, a aprendizagem não é valida somente na escola, ela vai muito além do "chão" desta Instituição, ganhando um aspecto essencial na formação do aluno, justamente ponto importante nessa relação.

Segundo dados históricos que foram submetidos no nosso estudo, à criação de escolas para a Educação Infantil começou no século XVIII, com a Revolução Industrial. A inserção da mulher no mercado de trabalho fez surgir os primeiros estabelecimentos de Educação Infantil no país, no final do século XIX. Eles eram filantrópicos até a década de 1920, quando se iniciou um movimento pela democratização do ensino. Aos poucos o poder público começou a assumir a responsabilidade pela escola dos pequenos. As creches populares atendiam somente o que se referia à alimentação, higiene e segurança física. (GENTILIN; REGINA. 2009).

Assim a educação na família e na escola não deve assumir caráter mecânico e sistemático, é preciso sim ensinar a criança a encontrar significado em cada momento de aprendizagem, levando cada ensinamento para a vida e que sejam incorporados a sua realidade. Nessa perspectiva, Chalita (2001, p. 120) destaca que: "a responsabilidade de educar não é apenas da escola, é de toda a sociedade, a começar pela família”. Ou seja, família e escola se complementam no processo de aprendizagem da criança.

Em 1988 a Constituição Federal destacou ponto a ponto a importância da família junto à formação de seus filhos não só no campo escolar, como também, em todo o meio que o mesmo habita. A Constituição de 1988 determinou a criação de uma legislação específica (BRASIL, 1988). Assim, em 1990, surgiu em nosso ordenamento jurídico o Estatuto da Criança e do Adolescente, conhecido como ECA (Brasil. 1990), a lhes garantir direitos específicos e políticas públicas de tratamento.

É importante ressaltar que essa legislação não deve tirar dos pais ou responsáveis a obrigação de trabalhar pela boa formação das crianças, os outros (sociedade e Estado) são apenas colaboradores desse processo tão importante para cada criança, variando de cultura, estilo de vida, religião e etc. O papel da escola é complementar toda forma de educação gerada pela família, seja ela qual for, ensinando a criança baseada nos conceitos de ética e cidadania, não se pode a escola 


\section{V.10 N.1 (2022) ISSN: 2317-434X}

assumir a responsabilidade total na formação de conceitos que devem ser da família, esses são compartilhados no dia a dia da relação das crianças com seus familiares, como por exemplo sua religião entre outros aspectos particulares do meio de convivência da criança (MARQUES, 1993).

A escola, principalmente na Educação Infantil, é o período em que a criança mais expande suas aptidões, conhecimentos e habilidades, sendo assim, fundamental para composição absoluta do homem. Mas é necessário destacar que outras instituições sociais também influenciam, também essenciais, na educação, como por exemplo, a família. É nela que os valores e costumes são vivenciados desde os primeiros momentos da vida da criança. E essa educação é ampliada quando caminha junto com a educação escolar. O papel da família na educação dos filhos é fundamental, pois é através dela que são passados os valores e afetos. Abrindo espaço para os diálogos e educando assim para a vida, construindo conhecimento envolvido para a sociedade, prevalecendo o respeito ao próximo (PESSANHA, 2014).

$\mathrm{O}$ processo de ensino aprendizagem vivenciado junto às aulas de Educação Física na Educação Infantil, é muito centrado na participação da família e da escola em todos os fatores do desenvolvimento integral da criança. A escola deve reconhecer e valorizar a importância da participação da família no contexto escolar e no desenvolvimento do aluno, de modo a auxiliá-la no cumprimento de suas funções em relação à educação, evolução e progresso dos filhos; sendo assim, propiciará, consequentemente, a transformação da sociedade. Dessa forma, o trabalho realizado em conjunto pelas duas instituições, família e escola, faz com que haja uma melhoria tanto no desenvolvimento escolar do aluno, quanto em suas relações em outros contextos sociais, tais como o âmbito familiar (DESSEN E POLONIA, 2005).

No outro lado o papel do professor é variado, complexo, mas motivador. Pretende-se que o professor de Educação Física atuando na Educação Infantil seja inovador, dinâmico, comunicativo, crítico e "eficaz." Ele deve ensinar, mas também educar, transmitir conhecimentos, mas também incutir métodos, instrumentos de trabalho e alguns valores fundamentais para que as crianças desde então já tenham esse direcionamento, como, por exemplo, a compreensão e o respeito pelo outro, a entreajuda ou a responsabilidade. $\mathrm{E}$ ainda desenvolver o espírito crítico, a reflexão, mas também a criatividade e a curiosidade em termos de aprendizagem que nesse ciclo é gigantesca (LUÍSA, 2012).

Para tanto, é necessário entender que dentro da escola, deve existir uma prática de abertura, comunicação intra e interpessoal, de diálogo e tolerância de compreensão e continuidade. Isto porque, querendo ou não, o professor projeta-se na criança e intervém sempre em sua vida. Cabe lembrar que a criança sê vê através dos olhos dos adultos, o conceito formado por ela de si mesma, dependerá muito do seu relacionamento ao longo da vida, com os pais e professores e da forma como será vista pelos mesmos. Assim, também como as palavras que ouvirá deles serão de instrumento que tanto pode ser empregada para o bem ou para o mal. Portanto, durante o processo de aprendizagem da criança, bem antes de sua entrada para escola, as pessoas que convivem com ela, principalmente os professores no relacionamento da sala de aula precisam ajudá-la a construir sua autoimagem, para que esta possa saber o que pensar de si mesma. Assim, aos poucos, é que os conceitos vão sendo construídos (BOTELHO, 2014).

A família tem um papel importante no desenvolvimento de cada pessoa, é com ela que acontecem as aprendizagens básicas, que são necessárias para o desenvolvimento autônomo dentro da sociedade. Apesar de ter muita influência, a família não consegue definir todas as características da criança, algumas são desenvolvidas a partir das experiências vividas por elas, outras dependem da carga hereditária ou de fatores alheios à vontade da família. $\mathrm{O}$ âmbito familiar funciona como uma rede de influências recíprocas entre todos que fazem parte dela. $\mathrm{O}$ estilo de comportamento dos familiares gera efeitos sobre o desenvolvimento social e da personalidade da criança. Independente de seu estilo de comportamento, os pais devem participar da administração escolar, contribuindo nas decisões mais relevantes, como por exemplo, a construção do Projeto Político Pedagógico. A gestão escolar participativa vem se caracterizando a partir da consideração de que um ambiente institucional escolar é formado, na realidade, por várias pessoas, que precisam estar em sintonia para alcançar os objetivos educacionais (MARTINS; TAVARES 2010).

\section{CONCLUSÃO}

A Educação Física na Educação Infantil proporciona à criança benefícios para sua formação, social, cognitiva, motora e afetiva, sendo importante também na formação de suas características e personalidade. Contudo, quando a família e escola se complementam o desenvolvimento integral da criança terá um leque maior de possibilidades de crescimento qualitativo, perante sua particularidade e tudo que o meio lhe oferece; cabe ao professor de Educação Física e a família procurarem atuar de forma que ajude esse processo direcionando a criança se desenvolver em toda sua amplitude, não apenas visando pontos isolados no processo de aprendizagem e desenvolvimento infantil. Em 


\section{V.10 N.1 (2022) ISSN: $2317-434 X$}

todas suas relações, a criança de 0 a 06 anos é praticamente um reflexo do que lhe é oferecido, de forma que a mesma incorpora em suas características, padrões, ações e atitudes.

Nesse sentido, o papel pedagógico da Educação Física nessa fase são associados ao que é oferecido durante toda a sua carreira dentro da Educação Infantil. A família tem que saber e acompanhar como o filho se comporta não só na escola, mas de maneira geral, sua base vem de casa e as aulas de Educação Física complementarão seu desenvolvimento integral, formando assim um aluno com níveis de desenvolvimento bem elaborados e um verdadeiro cidadão. Observa-se que a Educação Física tem um grande papel estimulante na vida da criança, as aulas proporcionadas pelo profissional de Educação Física no momento que os pequenos estão no ambiente escolar, ajudam a despertar nos praticantes os estímulos "ocultados" na correria do dia a dia da família em seu ambiente. As aulas de Educação Física desenvolvem vários fatores importantes para $\mathrm{o}$ crescimento $\mathrm{e}$ desenvolvimento das crianças, das mais variadas formas, como aspectos físicos, cognitivos, sociais e entre outros. Isso se comprova na relação do Profissional de Educação Física com os educandos da Educação Infantil, há um grande desejo em vivenciar momentos assim, onde elas se sentem muito em "casa", pois, o trabalho feito de forma que as convidem a querer mais, favorece essa relevância.

A família atuando com a escola dentro do processo de aprendizagem da criança contribui bastante em uma boa formação, que seja entrelaçada aos pontos que quando relacionado a cada particularidade, some e forneça seguimentos importantes para a relação da criança junto a sua própria casa e dentro do seu contexto escolar. Quando os familiares proporcionam momentos de lazer para os pequenos, eles estão unificando o trabalho, fazendo com que as crianças desfrutem de atividades saudáveis e educativas frequentemente, isso é uma forma altamente significativa de família e escola andarem juntas nesse processo, a criança ganha e muito, devemos traçar isso em cada convívio com os alunos.

Portanto, a participação da família de forma ativa e não apenas deixando o papel para a escola junto às aulas de Educação Física contribui diretamente com o processo de ensino aprendizagem, de forma que cada avanço é resultado da ajuda de um para com o outro (família/professor). E nesse sentido devemos quanto professores de Educação Física atuar na Educação Infantil promovendo o que a criança merece obter no seu desenvolvimento integral, observando a sua importância no processo de ensino aprendizagem. Logo, a família é a grande referência da vida de todos, ajudando como complemento de costumes saudáveis, como dar liberdade de brincar, levar para parques, estimular também os jogos de salão e educativos, onde Educação Física e família formam uma base sólida para a aprendizagem e desenvolvimento das crianças de 06 a 06 anos.

\section{REFERÊNCIAS}

ARAUJO, Rita; FLORIANA, Magda. Vygotsky e as teorias da aprendizagem: Pelotas. Unirevista, 2006.

ANTUNES, Celso. A linguagem do afeto: como ensinar virtudes e transmitir valores. Campinas, São Paulo. Papirus, 2005.

AYOUB, E. Narrando Experiências com a Educação Física na Educação Infantil,

Revista Brasileira de Ciências do Esporte, Campinas, v. 6, n. 3, p. 143-158, maio, 2005.

ARIÉS, P. História social da criança e da família. 2.ed. Rio de Janeiro: Zahar, 1981.

BEDINI, Glauber. A família, a escola e a Educação Física: suas relações no processo

Educacional. EFDeportes.com, Revista Digital. Buenos Aires, Año 15, № 150, Novembro de 2016.

BRASIL. Estatuto da Criança e do Adolescente. Lei ${ }^{\circ}$
8069, de julho de 1990.

BRASIL. Constituição da República Federativa do Brasil. Brasília: Senado Federal, 1988.

BRASIL. Ministério da Educação e do Desporto. Secretaria de Educação Fundamental. Referencial Curricular Nacional para a Educação Infantil. Brasília: MEC/SEF, 1998.

BRASIL. Ministério da Educação. Lei de Diretrizes e Bases da Educação Nacional-LDB. Lei Darcy Ribeiro 9.394/96. Brasília-1996.

BOCCATO, V. R. C. Metodologia da pesquisa bibliográfica na área odontológica e o artigo científico como forma de comunicação. Rev. Odontol. Univ, São Paulo, v. 18, n.3, 2006.

BOTELHO, Robson. Família e escola: uma parceria 


\section{V.10 N.1 (2022) ISSN: 2317-434X}

para o processo ensino aprendizagem. Campos dos Goytacazes/Rio de janeiro: Instituto Federal de Educação Ciência e Tecnologia Fluminense Campus, 2014.

CHALITA, G. Educação: A solução está no afeto. São Paulo: Gente, 2001.

CRAIDY, Carmen; KAERCHER, Gládis. Educação Infantil pra que te quero? $1^{a}$ edição. Porto Alegre: Artmed, 2001.

CORSARO, W. Nós somos amigos , certo ?: dentro culturas infantis. Washington, DC: Joseph Henry, de 2003.

DESSEN, Maria Auxiliadora; POLONIA, Ana da Costa. A família e a escola como contextos de desenvolvimento humano. Paidéia (Ribeirão Preto) [online]. 2007, vol.17, n.36, pp. 21-32. ISSN 0103-863X. Disponível em: http://dx.doi.org/10.1590/S0103- 863X2007000100003. Acesso em: 25 setembro 2013.

FERREIRA, A.B. de H. Novo dicionário Auréli de língua portuguesa. Rio de Janeiro: Nova Fronteira, 1986.

GALVÃO, Izabel. Uma reflexão sobre o pensamento pedagógico de Henri Wallon. In: Cadernos Idéias, construtivismo em revista. São Paulo, F.D.E., 1995.

GENTILIN, Adriana; REGINA, Verônica. Educação Física na Educação Infantil: uma realidade almejada. Curitiba: UFPR, 2009.

KAMII, Constance. Jogos em grupo na Educação Infantil: implicações da teoria de Piaget. São Paulo: Trajetória Cultural, 1991.

LUÍSA, Ana. A relação entre escola e família as suas implicações no processo de ensino aprendizagem. Lisboa: Escola superior de educação João de deus, 2012.

LEFRANÇOIS, Guy R. Teorias da Aprendizagem. Tradução: Vera Magyar. $5^{\mathrm{a}}$ edição. São Paulo: Cengage
Learning, 2008.

MARQUES, R. A escola e os pais como colaborar?. São Paulo. Texto Editora. $4^{\mathrm{a}}$ ed. 1993.

MARTINS, Sandra; TAVARES, Helenice. A família e a escola: desafios para a educação no mundo contemporâneo. Uberlândia: Revista Católica, 2010.

PÁDUA, Luiz de. A epistemologia genética de Jean Piaget. Revista FACEVV. Disponível em: http://facevv.cnec.br/wpcontent/uploads/sites/52/2015/10/A-EPISTEMOLOGIAGENETICA.pdf. Acesso em: 14 out. 2016.

PIAGET, Jean. A formação do símbolo na criança. $3^{\mathrm{a}}$ ed. Rio de Janeiro: Zahar, 1971.

PIAGET, Jean. Seis estudos de Piaget. Tradução: Maria Alice Magalhães D’Amorim e Paulo Sérgio Lima Silva. $25^{\mathrm{a}}$ ed. Rio de Janeiro: Forense Universitária, 2011.

PESSANHA, Gabrielle. Tecendo ideias sobre a importância da relação família e escola na infância. Rio de Janeiro: Centro de ciências humanas e sociais, 2014.

PEREZ, M. C. A. Infância, família e escola: práticas educativas e seus efeitos no desempenho escolar de crianças das camadas populares. São Carlos, SP: Suprema, 2007.

SCHETTINI FILHO, Luiz. A criança de 6 a 10 anos: na família e na escola. Recife. Bagaço, 1997.

SOARES, J. M. Família e Escola: Parceiras no Processo Educacional Da Criança. IESAP. Amapá, 2010.

VYGOTSKY, L.S. Formação social da mente. São Paulo: Martins Fontes, 1984.

WALLON, Henri. Psicologia e Educação da Infância. Lisboa: Estampa. 1995. 